\title{
Comparative Assessment of Haematological Changes Among Workers Exposed to Rice Husk Dust at Abakaliki Rice Mill
}

\author{
Ejike Felix Chukwurah $^{1 *}$, Celestine O Igwe ${ }^{2}$, Felix Chinedum Chukwurah ${ }^{3}$, Onyekachi Ewa Ibe ${ }^{4}$, Anil Tukaram Pawar ${ }^{5}$ \\ ${ }^{1}$ Haematology \& Immunology Unit, Dept. of Medical Laboratory Sciences, Faculty of Health Sciences \& Technology, Ebonyi State University, \\ Abakaliki - Nigeria \\ ${ }^{2}$ Dept. of Medical Laboratory Sciences, Faculty of Health Sciences \& Technology, Ebonyi State University, Abakaliki - Nigeria \\ ${ }^{3}$ Shenyang Medical College, Shenyang Liaoning P.R. China/Dept of Surgery, Enugu State University Teaching Hospital, Enugu - Nigeria \\ ${ }^{4,5}$ Haematology \& Immunology Unit, Dept. of Medical Laboratory Sciences, Faculty of Health Sciences \& Technology, Ebonyi State University, \\ Abakaliki - Nigeria
}

DOI: $10.36348 /$ sijap.2020.v03i05.001 | Received: 16.05.2020 | Accepted: 23.05.2020 | Published: 25.05 .2020

*Corresponding author: Ejike Felix Chukwurah

\section{Abstract}

Background: Rice is currently the major stable food for most Nigerians and rice farming and local processing has become popular with the recent ban on importation. Health hazards associated with occupational exposure to rice husk dust have been documented even among developed countries with advanced technology in rice processing. Aim: We assessed possible effect of longtime exposure to husk dust on some haematological parameters. Methods: A crosssectional, descriptive and analytical study was conducted at Abakaliki Rice Mill, Ebonyi State -Nigeria on 80 workers (male36, female 44) between 18-61years and 56 age/sex-matched manual workers not exposed to husk dust. The haematological parametes; PCV, ESR, total and differential leucocyte counts were estimated using standard methods. Results: Majority of the workers were female. There were significant differences in PCV, ESR and differential leucocyte counts $(\mathrm{P}>0.05)$ between workers exposed to rice husk dust and control. The total WBC count did not show any significant difference when compared. However significant increases were observed in the relative WBC differentials in lymphocytes, monocyte and eosinophil counts and significant decrease in differential neutrophil count. Significant relationships were observed between ESR/neutrophil, ESR/lymphocyte and neutrophil/lymphocytes in both exposed workers and control. Conclusion: Exposure to rice husk dust is significantly associated with variations in haematological parameters and invariably health status. Therefore improved occupational health safety through the use of personal protective equipment and regular health check is advocated.

Keywords: Rice husk dust, Haematological parameters, occupational safety.

Copyright @ 2020: This is an open-access article distributed under the terms of the Creative Commons Attribution license which permits unrestricted use, distribution, and reproduction in any medium for non-commercial use (NonCommercial, or CC-BY-NC) provided the original author and source are credited.

\section{INTRODUCTION}

Rice is currently the major stable food for most Nigerians [1] and indeed Africans and rice farming and processing has become popular especially as the Nigerian government has made effort in recent times to improve on rice production by banning the importation of foreign rice into the country. This led to aggressive rice farming and establishment of small and medium scale rice processing industries. Abakaliki Rice Mill is one of the largest rice processing industries in Ebonyi Statae, Nigeria. It is manned and operated by individual investors, contributes to the economic and social development, one of the major employers of labour and source of government internally generated revenue. The processing is labour intensive and women represent a large proportion of the manual workers.
Rice milling is the process of extraction of rice grain from paddy; removal of outmost hull/husk, bran layer and an innermost starchy endosperm/kernel. rice grain from the paddy In processing, a substantial amount of products such as husk dust, microbial particles, mineralogical materials (dust, fumes, ashes or other industrial waste) may be released into the environment and constitute toxic elements that may cause health risk to workers. Risks of occupational exposures to dust and effects on haematological parameters have been observed in our previous studies $[2,3]$.

Evidence studies on occupational hazards of rice processing has been documented [4-8] and shown to cause increased respiratory symptoms such as 
allergic alveolitis [5], poor lung function [8] and release of inhalable genotoxic aflatoxin [5,9] Husk dust and other intermediate waste generated depend on the mill setting and equipments. The Abakaliki Rice Mill is majorly operated semi manually and most of the workers are of low-income, uneducated women with little or no knowledge of health implication of their trade and necessary safety precautions. This study therefore will possibly educate and demonstrate the extensive need for preventive measures through the use of personal preventive equipments.

Haematological parameters have been clinically utilized in assessing health and nutritional status at different conditions [10-12] and indeed occupational exposures to dust and chemicals with varied results [13-15]. Evaluation of haematological parameters and inflammatory markers of workers at different occupational exposures may help in assessing pulmonary function, respiratory and allergic responses and associated pathology and indeed general wellbeing. This study therefore is an evidence-base intervention towards public health and safety awareness and proper management of diseases associated with exposure to rice husk dust.

\section{METHODS}

\section{Subjects and Sampling}

This cross-sectional, descriptive and analytical study was conducted at Abakaliki Rice Mill, Ebonyi State -Nigeria. Only workers involved in milling, grading, de-stoning and packaging of rice and constantly exposed to husk dust for more than one year were sampled for some haematological parameters (PCV, ESR, total and differential leucocyte counts). Written informed consent was obtained from each participant and study protocol was approved by the Trade Union Executive and Ebonyi State University Ethical Review Committee. Strict anonymity was observed throughout the study and intervention programmed aimed at educating the workers on the safety and health implications of their work instituted. Sample size was calculated using the method of Cochran [16].

A total of 136 individuals comprised of 80 rice processing workers (male, 36; female 44) between 18 -
61 years and 56 age/sex-matched manual workers not exposed to rice husk dust as control population were sampled between November, 2019 to January, 2020. Workers with less than one year experience were excluded. Five milliliters of blood was collected from each participant into EDTA bottle for the assay and analyzed without storage.

\section{Measurements of variables}

The PCV, ESR, total WBC and differential counts were done without preservation using standard methods. Data were analyzed using Pearson correlation and Student T-test, adapted from Statistical Package for Social Sciences (SPSS) version 22 and Microsoft excel software. Statistical significance was set at $\mathrm{p}<0.05$. Volunteer's age, contact details and analysis were stored in a password protected computer. During processing and analysis all samples were recognized by the laboratory number without any detail of the volunteer. Each volunteer's results were communicated to him/her only.

\section{RESULTS}

Apart from few workers that operate the machines; women represent a large proportion of the workers. There were significant differences in PCV, ESR and differential leucocyte counts ( $P>0.05)$ between workers exposed to rice husk dust and control (Table 1). The mean ESR of experimental group (exposed workers) was $45.69 \mathrm{~mm} / \mathrm{Hg}$ more than the control group. The total WBC count did not show any significant difference when compared. However significant increases were observed in the relative WBC differentials in lymphocytes, monocyte and eosinophil counts and significant decrease in differential neutrophil count.

No significant relationship $(\mathrm{P}>0.05)$ were observed between the PCV and other parameters (ESR, total WBC and differentials) in both control and exposed workers as well as between total WBC and other parameters (Table $2 \quad \& \quad 3$ ). Significant relationships were observed between ESR/neutrophil, ESR/lymphocyte and neutrophil/lymphocytes in both exposed workers and control Tables $2 \& 3$, Figs 1, 2, \& 3)

Table-1: Comparison of the difference between the haematological parameters of the experimental group and control group

\begin{tabular}{|l|l|l|c|l|c|c|}
\hline & Control & Experimental & & & & \\
\hline Parameters & Mean \pm Std & Mean \pm Std & Mean Diff & df & t & P-value \\
\hline PCV $(\%)$ & $40.00 \pm 2.24$ & $34.28 \pm 3.30$ & 5.73 & 134 & 11.285 & 0.000 \\
\hline ESR $(\mathrm{mm} / \mathrm{Hg})$ & $11.13 \pm 5.59$ & $56.81 \pm 26.88$ & -45.69 & 134 & -12.518 & 0.000 \\
\hline WBC $\left(\mathrm{X} 10^{9} / \mathrm{L}\right)$ & $4.66 \pm 1.14$ & $5.02 \pm 1.44$ & -0.36 & 134 & -1.543 & 0.125 \\
\hline Neut $(\%)$ & $63.30 \pm 10.57$ & $39.75 \pm 11.50$ & 23.55 & 134 & 12.148 & 0.000 \\
\hline Lymph $(\%)$ & $34.09 \pm 11.83$ & $56.38 \pm 10.82$ & -22.30 & 134 & -11.381 & 0.000 \\
\hline Mono (\%) & $0.61 \pm 0.87$ & $1.30 \pm 2.13$ & -0.69 & 134 & -2.301 & 0.023 \\
\hline Eosino (\%) & $0.66 \pm 0.92$ & $2.75 \pm 2.99$ & -2.09 & 134 & -5.063 & 0.000 \\
\hline
\end{tabular}

Key: PCV - packed Cell volume, WBC - White blood cell, Neut - neutrophil, Lymph - Lymphocyte, Mono - Monocyte, Eosino - Eosinophil 
Table-2: Relationship between the haematological parameters of the control groups

\begin{tabular}{|c|c|c|c|c|c|c|c|c|}
\hline \multicolumn{9}{|c|}{ Correlations $^{\mathrm{a}}$} \\
\hline & & PCV & ESR & WBC & Neut & Lymph & Mono & Eosino \\
\hline \multirow[t]{3}{*}{$\mathrm{PCV}(\%)$} & $\mathrm{r}$ & 1 & -.182 & -.002 & -.123 & .117 & -.131 & .035 \\
\hline & $\mathrm{P}$-value & & .181 & .988 & .367 & .392 & .336 & .796 \\
\hline & $\mathrm{N}$ & 56 & 56 & 56 & 56 & 56 & 56 & 56 \\
\hline \multirow[t]{3}{*}{ ESR (mm/Hg) } & $\mathrm{r}$ & -.182 & 1 & .064 & $.324^{*}$ & $-.355^{* *}$ & .115 & .199 \\
\hline & P-value & .181 & & .639 & .015 & .007 & .397 & .141 \\
\hline & $\mathrm{N}$ & 56 & 56 & 56 & 56 & 56 & 56 & 56 \\
\hline \multirow[t]{3}{*}{$\mathrm{WBC}\left(\mathrm{X} 10^{\wedge} 9 / \mathrm{L}\right)$} & $r$ & -.002 & .064 & 1 & -.164 & -.086 & -.093 & .103 \\
\hline & P-value & .988 & .639 & & .228 & .529 & .495 & .450 \\
\hline & $\mathrm{N}$ & 56 & 56 & 56 & 56 & 56 & 56 & 56 \\
\hline \multirow[t]{3}{*}{ Neut (\%) } & $\mathrm{r}$ & -.123 & $.324^{*}$ & -.164 & 1 & $-.916^{* *}$ & .233 & .170 \\
\hline & $\mathrm{P}$-value & .367 & .015 & .228 & & .000 & .083 & .211 \\
\hline & $\mathrm{N}$ & 56 & 56 & 56 & 56 & 56 & 56 & 56 \\
\hline \multirow[t]{3}{*}{ Lymph (\%) } & $\mathrm{r}$ & .117 & $-.355^{* * *}$ & -.086 & $-.916^{* *}$ & 1 & $-.298^{*}$ & $-.371^{* *}$ \\
\hline & P-value & .392 & .007 & .529 & .000 & & .026 & .005 \\
\hline & $\mathrm{N}$ & 56 & 56 & 56 & 56 & 56 & 56 & 56 \\
\hline \multirow[t]{3}{*}{ Mono (\%) } & $\mathrm{r}$ & -.131 & .115 & -.093 & .233 & $-.298^{*}$ & 1 & .103 \\
\hline & $\mathrm{P}$-value & .336 & .397 & .495 & .083 & .026 & & .448 \\
\hline & $\mathrm{N}$ & 56 & 56 & 56 & 56 & 56 & 56 & 56 \\
\hline \multirow[t]{3}{*}{ Eosino (\%) } & $\mathrm{r}$ & .035 & .199 & .103 & .170 & $-.371^{* *}$ & .103 & 1 \\
\hline & P-value & .796 & .141 & .450 & .211 & .005 & .448 & \\
\hline & $\mathrm{N}$ & 56 & 56 & 56 & 56 & 56 & 56 & 56 \\
\hline \multicolumn{9}{|c|}{ *. Correlation is significant at the 0.05 level (2-tailed). } \\
\hline \multicolumn{9}{|c|}{ **. Correlation is significant at the 0.01 level (2-tailed). } \\
\hline \multicolumn{9}{|l|}{ a. Group $=$ Control } \\
\hline
\end{tabular}

Table-3: Relationship between the haematological parameters of the Experimental groups

\begin{tabular}{|c|c|c|c|c|c|c|c|c|}
\hline \multicolumn{9}{|c|}{ Correlations $^{\text {a }}$} \\
\hline & & $\mathrm{PCV}$ & ESR & WBC & Neut & Lymph & Mono & Eosino \\
\hline \multirow[t]{3}{*}{$\operatorname{PCV}(\%)$} & $\mathrm{r}$ & 1 & -.152 & .143 & -.186 & .174 & .143 & -.052 \\
\hline & P-value & & .180 & .205 & .099 & .123 & .206 & .647 \\
\hline & $\mathrm{N}$ & 80 & 80 & 80 & 80 & 80 & 80 & 80 \\
\hline \multirow[t]{3}{*}{ ESR (mm/Hg) } & $\mathrm{r}$ & -.152 & 1 & .012 & $-.273^{*}$ & $.282^{*}$ & -.005 & .059 \\
\hline & P-value & .180 & & .913 & .014 & .011 & .962 & .604 \\
\hline & $\mathrm{N}$ & 80 & 80 & 80 & 80 & 80 & 80 & 80 \\
\hline \multirow[t]{3}{*}{$\mathrm{WBC}\left(\mathrm{X} 10^{\wedge} 9 / \mathrm{L}\right)$} & $\mathrm{r}$ & .143 & .012 & 1 & .096 & -.069 & $-.259^{*}$ & .037 \\
\hline & P-value & .205 & .913 & & .398 & .541 & .020 & .743 \\
\hline & $\mathrm{N}$ & 80 & 80 & 80 & 80 & 80 & 80 & 80 \\
\hline \multirow[t]{3}{*}{ Neut (\%) } & $\mathrm{r}$ & -.186 & $-.273^{*}$ & .096 & 1 & $-.941^{* * *}$ & -.014 & $-.247^{*}$ \\
\hline & $\mathrm{P}$-value & .099 & .014 & .398 & & .000 & .902 & .027 \\
\hline & $\mathrm{N}$ & 80 & 80 & 80 & 80 & 80 & 80 & 80 \\
\hline \multirow[t]{3}{*}{ Lymph (\%) } & $\mathrm{r}$ & .174 & $.282^{*}$ & -.069 & $-.941^{* * *}$ & 1 & -.130 & -.003 \\
\hline & P-value & .123 & .011 & .541 & .000 & & .249 & .980 \\
\hline & $\mathrm{N}$ & 80 & 80 & 80 & 80 & 80 & 80 & 80 \\
\hline \multirow[t]{3}{*}{ Mono (\%) } & $\mathrm{r}$ & .143 & -.005 & $-.259^{*}$ & -.014 & -.130 & 1 & .004 \\
\hline & $\mathrm{P}$-value & .206 & .962 & .020 & .902 & .249 & & .972 \\
\hline & $\mathrm{N}$ & 80 & 80 & 80 & 80 & 80 & 80 & 80 \\
\hline \multirow[t]{3}{*}{ Eosino (\%) } & $\mathrm{r}$ & -.052 & .059 & .037 & $-.247^{*}$ & -.003 & .004 & 1 \\
\hline & P-value & .647 & .604 & .743 & .027 & .980 & .972 & \\
\hline & $\mathrm{N}$ & 80 & 80 & 80 & 80 & 80 & 80 & 80 \\
\hline \multicolumn{9}{|c|}{ *. Correlation is significant at the 0.05 level (2-tailed). } \\
\hline \multicolumn{9}{|c|}{ **. Correlation is significant at the 0.01 level (2-tailed). } \\
\hline \multicolumn{9}{|c|}{ a. Group = Control } \\
\hline
\end{tabular}




\section{Relationships}

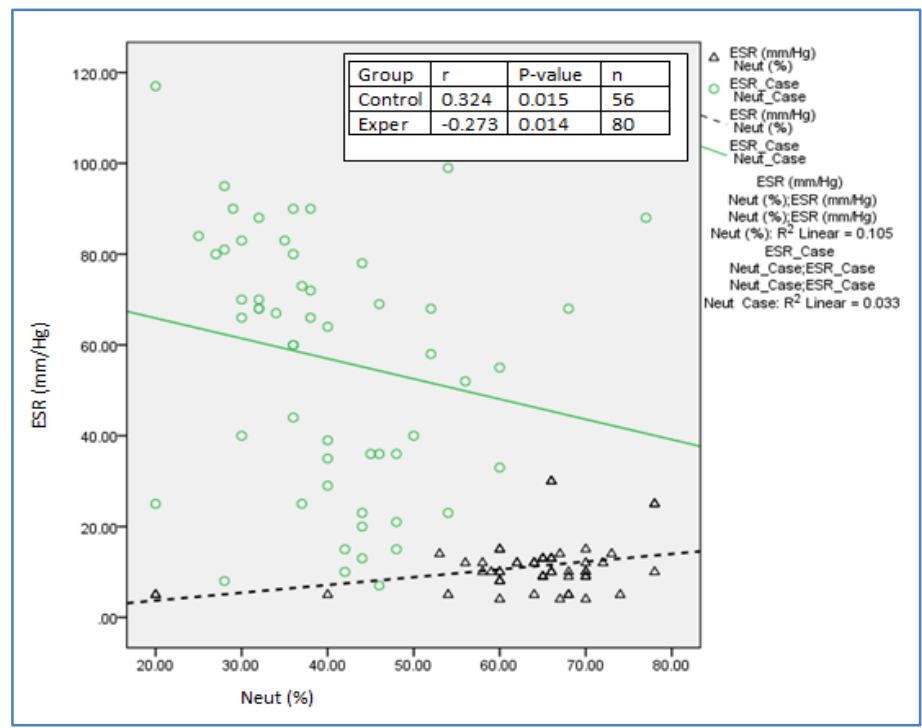

Fig-1: Chart showing the relationship between ESR (mm/Hg) and Neut (\%) between the control and experimental group.

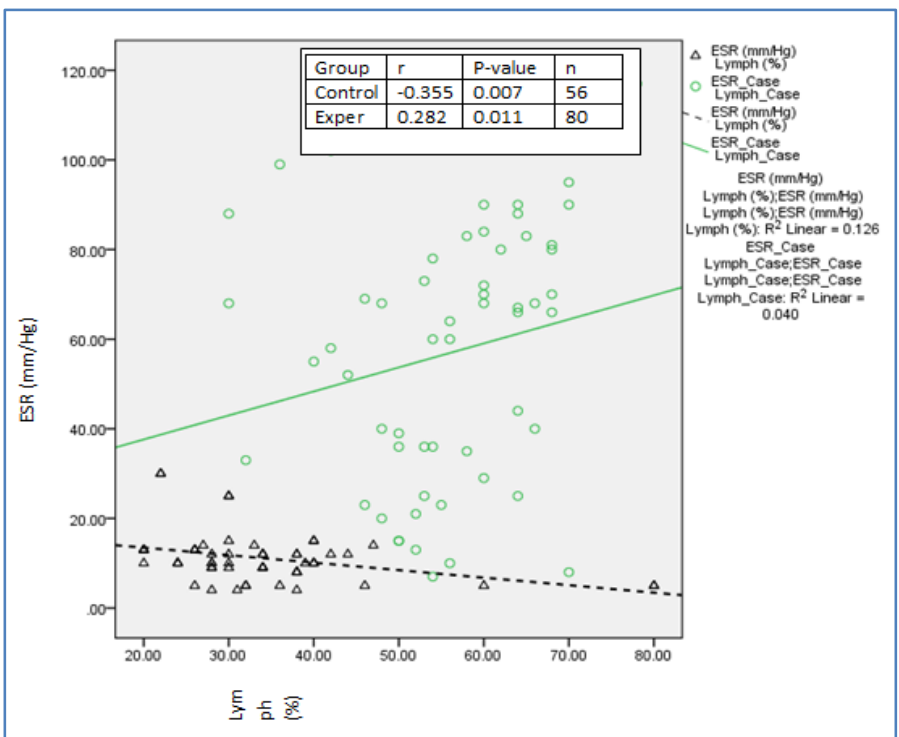

Fig-2: Chart showing the relationship between ESR $(\mathrm{mm} / \mathrm{Hg})$ and Lymph (\%) between the control and experimental group

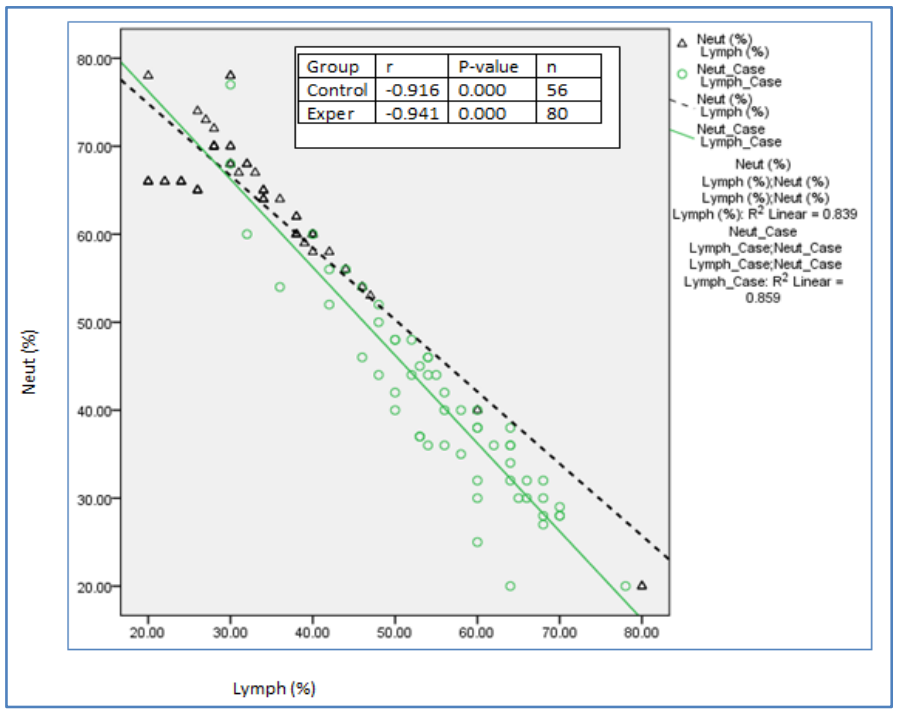

Fig-3: Chart showing the relationship between Neutrophil (\%)) and Lymphocyte (\%) between the control and experimental group 


\section{CONCLUSION}

Health risks of occupational exposure to rice husk dust and other irritants has been documented (1719) and shown to play a major role in the aggravation of respiratory and lung diseases. In rice milling especially the non-mechanized type; exposure to dusts of organic, inorganic, bacterial, viral toxins and lipoplysaccharides may be associated with some health risks and have potentials to activate eosinophils and inflammatory responses. This impacts negatively on the productivity or efficiency of workers and present with social, health and economic implications. Awareness on the health risk and education on the use of personal preventive equipments no doubt will help.

Occupational exposure to rice husk dust has been shown to affect the lung function and associated with some respiratory and allergic diseases [5,18]. Activation of eosinophil and the inflammatory responses may be contributory and previous authors observed changes in some haematological and inflammatory markers in workers exposed to husk dust [5,17]. Significant elevations in eosinophil, lymphocytes, monocytes and basophils have been observed in exposed workers than unexposed nonsmokers. Varied results in total leucocyte counts were previously recorded $[17,18]$.

Possible mechanism for the aggravation of respiratory diseases was through smoke dust that contains bacterial lipolysaccharide and several chemical irritants such as formaldehyde and acetaldehyde making the rice husk dust and its smoke hazardous air pollutants [19]. This is thought to contribute clinically to respiratory distress and inflammatory reactions associated with exposure to rice husk. Some inflammatory markers have been previously investigated in occupational exposures, chronic diseases and even in malnutrition and found to be of clinical utility [12,20,21]. Among these were ESR, total leucocyte count, albumin, C-reactive protein and proinflammatory cytokines (TNF- $\alpha$, IL-1, IL-6) and their soluble receptors with contradicting results.

In this study, evidence-based comparative analysis was done on haematological parameters among workers exposed to rice husk dust and other contaminants at the work place. Significant variations were observed in PCV, ESR and differential leucocyte counts. This is in agreement with previous studies in dust exposed workers [2,3,5,17]. Significant relationships were equally observed between the ESR with neutrophil and lymphocyte when compared with control. This is in line with observations of previous authors in different disease conditions [10,11,13,22] and suggests the clinical utility of these markers in management of diseases. The ESR has shown to be a good predictor in accessing general health of workers exposed to husk dust.
It was observed also that workers in the rice mill do not abide to the safety measures. Personal protective equipments were not in use further exposing workers to health risks. This is worrisome and should be discouraged. Adequate health policy therefore is necessary for improved health and safety of workers.

\section{Conclusion}

Significant differences were observed in the mean values of PCV, ESR and differential leucocyte count when compared with controls. There appeared association between the ESR and neutrophil, lymphocyte and eosinophil. Practice of better work safety through the use of personal protective equipment and regular health check is advocated.

\section{Acknowledgment}

We gratefully acknowledge the help of the entire participants who took part in the study.

\section{Conflict of Interests} of interest.

The authors declare that they have no conflict

\section{REFERENCES}

1. Agha, E.O., \& Ekpenyong, O. (2018). Sociodemographic Predictors of Job Involvement of Rice Mill Workers in Abakaliki, Ebonyi State. Nigeria International Journal of Economic Development Research and Investment, 9(1): 1-20.

2. Felix, C. E., Frances, E. R., \& Chinedum, C. F. Assessment of ESR, Serum Protein and Body Mass Index among quarry workers at Okposi Umuoghara, Ezza North Local Government Area of Ebonyi State-Nigeria.

3. Chukwurah, E.F., Nwambeke, W.N., Chukwurah, F.C (2020). Effects of Quarry Dust on Some Haematological Parameters among Workers at Okposi Umuoghara, Ebonyi State - Nigeria. Saudi Journal of Biomedical Research, 5(5): 82-86.

4. Musa, R., Naing, L., Ahmad, Z. U. L. K. I. F. L. I., \& Kamarul, Y. (2000). Respiratory health of rice millers in Kelantan, Malaysia. Southeast Asian journal of tropical medicine and public health, 31(3), 575-578.

5. Ghosh, T., Gangopadhyay, S., \& Das, B. (2014). Prevalence of respiratory symptoms and disorders among rice mill workers in India. Environmental health and preventive medicine, 19(3), 226-233.

6. Mohammadyan, M., Ranjbar, F., Etemadinezhad, S., \& Charati, J. Y. (2017). Risk assessment of rice husk dust among rice mill workers. FRESENIUS ENVIRONMENTAL BULLETIN, 26(1 A), 892-897.

7. Wickramage, S. P., Rajaratne, A. A. J., \& Udupihille, M. (2017). Are Rice Millers an At-Risk Group for Lung Disease?-An Occupational Health Concern in Rural Sri Lanka. Indian J Physiol Pharmacol, 61(4), 340-347.

8. Rajapakse, S., Wickramage, S. (2019). Evaluation of the occupational hazard of rice husk dust particle 
exposure on lung function. Conference: Asia Pacific Academic Consortium for Public Health Early Career Global Health Conference At: University of Malaya, Kuala Lumpur, Malayasia.

9. Desai, M. S., \& Ghosh, S. K. (1989). Aflatoxin related occupational hazards among rice mill workers. Journal of Toxicology: Toxin Reviews, 8(1-2), 81-87.

10. Valmari, P. (1984). White blood cell count, erythrocyte sedimentation rate and serum Creactive protein in meningitis: magnitude of the response related to bacterial species. Infection, 12(5), 328-330.

11. Kim, Y. H., Woo, S. H., Lee, W. J., Seol, S. H., Kim, D. H., Lee, J. Y., \& Choi, S. P. (2017). High white blood cell count and erythrocyte sedimentation rate are associated with perforated appendicitis in children. Pediatric Emergency Medicine Journal, 4(2), 51-57.

12. Felix, C. E., Ogodo, N. D., \& Ngozi, A. A. (2003). Evaluation of body mass index, hematocrit, erythrocyte sedimentation rate and total protein in voluntary and commercial blood donors in Nigeria: Advocating for simultaneous screening for nutritional status. Int J Blood Transfus Immunohematol, 7, 26-32.

13. Balestrino, M., Partinico, D., Finocchi, C., \& Gandolfo, C. (1998). White blood cell count and erythrocyte sedimentation rate correlate with outcome in patients with acute ischemic stroke. Journal of Stroke and Cerebrovascular Diseases, 7(2), 139-144.

14. Ye, J. K., Zhang, J. T., Kong, Y., Xu, T., Zou, T. T., Zhang, Y. H., \& Zhang, S. Y. (2012). Relationship between white blood cell count, neutrophils ratio and erythrocyte sedimentation rate and short clinical outcomes among patients with acute ischemic stroke at hospital admission. Zhonghua liu xing bing xue za zhi= Zhonghua liuxingbingxue zazhi, 33(9), 956-960.

15. Rana, M. C., Naskar, S., Roy, R., Das, D. K., \& Das, S. (2018). Respiratory morbidity among rice mill workers in an urban area of Burdwan District, West Bengal: A cross-sectional study. Indian journal of occupational and environmental medicine, 22(1), 5.

16. Cochran,W.G. (1997). Sampling techniques (3rd ed). New York: John Wiley \& sons.

17. Patil, P. S., Aithal, M., Pujari, V. M., \& Das, K. K. (2016). Effect of Occupational Exposure on WBC Count and Oxidative Stress in Rice Mill Workers. Journal of krishna institute of medical sciences university, 5(1), 27-31.

18. Al-Katib, S. R., \& Al-Hakkak, Z. M. (2016). Pulmonary Function, Hematological Parameters and Inflammatory Markers in Workers Exposed to Wheat Flour Dust in Najaf City. Am. J. Res. Comm, 4(10), 1-9.

19. Kayaba, H., Meguro, H., Muto, H., Kamada, Y., Adachi, T., Yamada, Y., ... \& Chihara, J. (2004). Activation of Eosinophils by rice-husk dust exposure: a possible mechanism for the aggravation of asthma during rice harvest. The Tohoku journal of experimental medicine, 204(1), 27-36.

20. Felix, C. E., Ehigiator, I. F., \& Chinedum, C. F. (2018). Pro-inflammatory cytokines (TNF- $\alpha$ and IL-1) in Nigerian women with breast cancer. Open Journal of Immunology, 8(2), 13-28.

21. Van Atteveld, V. A., Van Ancum, J. M., Reijnierse, E. M., Trappenburg, M. C., Meskers, C. G., \& Maier, A. B. (2019). Erythrocyte sedimentation rate and albumin as markers of inflammation are associated with measures of sarcopenia: a cross-sectional study. BMC geriatrics, 19(1), 233.

22. Ong, E., Farran, S., Salloum, M., Gardner, S., Giovinco, N., Armstrong, D., \& Mohajer, M. A. (2015, December). The role of inflammatory markers: WBC, CRP, ESR, and neutrophil-tolymphocyte ratio (NLR) in the diagnosis and management of diabetic foot infections. In Open Forum Infectious Diseases (Vol. 2, No. suppl_1). Oxford University Press. 